\title{
Mitigation of Power Oscillations Using UPFC with Intelligent Technique
}

\author{
K.Saravanan ${ }^{1}$, Dr. R. Anita ${ }^{2}$, Dr. C. Manoharan ${ }^{3}$ and M.Arulvizhi ${ }^{4}$ \\ ${ }^{1}$ Assistant Professor, Department of Electrical and Electronics Engineering, Paavai college of Engineering, \\ India, \\ ${ }^{2}$ Professor\& Head, Department of Electrical and Electronics Engineering, IRTT, India \\ ${ }^{3}$ Principal, AMS Engineering College, India \\ ${ }^{4}$ Assistant Professor, Narasu's Sarathy Institute of Technology, India.
}

\begin{abstract}
In addition to steady-state power flow control, damping oscillations in a power network is one of the primary applications of a Unified Power Flow Controller (UPFC).Mitigation of the power oscillations is accomplished by changing the power flow through the series part of the UPFC. Newton Raphson algorithm is implemented for load flow studies. The parameters of UPFC are optimized using Particle Swarm Optimization algorithm. Installation of UPFC with such optimal parameters will minimize the overloaded lines and the bus voltage destructions under critical contingencies. Validation through the implementation on the IEEE-14 bus and IEEE-30 bus system shows that the PSO based UPFC is found feasible to achieve the task. The simulation results of the network with and without using UPFC is compared with GA a challenge to highlight the merit of the proposed PSO based UPFC controller.
\end{abstract}

Keywords: - Stability, Flexible ac transmission systems, Unified Power Flow Controller, Voltage Stability Index, Particle Swarm Optimization.

\section{Introduction}

The power system is an exceedingly nonlinear system that operates in a constantly changing environment; loads, generator outputs, topology, and key operating parameters change continually. The system must be able to operate satisfactorily under these conditions and successfully meet the load demand. It must also be able to survive numerous disturbances of a severe nature, such as a short-circuit on a transmission line; loads are adding or falling and loss of a large generator. Further, devices used to protect individual equipment may respond to variations in system variables and thereby affect the power system performance. Hence, instability in a power system may occur in many different ways depending on the system topology, operating mode, and the form of the disturbance. Instability that may result occurs in the form of a progressive fall or rise of voltage of some buses. The possible outcome of voltage instability is loss of load in the area where voltages reach unacceptably low values, or a loss of integrity of the power system.

In order to expand or enhance the power transfer capability of existing transmission network the concepts of FACTS (Flexible AC transmission system) is developed by the Electric Power Research Institute (EPRI) in the late 1980s. The main objective of FACTS devices is to replace the existing slow acting mechanical controls required to react to the changing system conditions by rather fast acting electronic controls. FACTs means alternating current transmissions systems incorporating power electronic based and other static controllers to enhance controllability and increase power transfer capability [1].FACTS devices provide innovative control facilities, both in steady state power control and dynamic stability control [3].There are various forms of FACTS devices, some of which are connected in series with a line and the others are connected in shunt or a combination of series and shunt. The UPFC allowing independent control of the voltage magnitude, and the real and reactive power flows along a given transmission line. In general, conventional optimization methods are unable to locate the global optimum but only locate the local optimum. The premature convergence of genetic algorithm [5] degrades the performance and reduces its search capability, by which it leads a higher property of local minimum. The Particle Swarm Optimization (PSO) can generate high quality solutions within short time with a high global searching ability at the beginning of iteration and the local search at the end of the iteration [4]. Therefore, in this paper PSO is used for loss minimization incorporating UPFC.

\subsection{Related Works} this section.

Some of the recent research works related to power stability using FACTS controller are discussed in

Sharma et al. [12] have focused on the damping of power system oscillations of the single and multi machine power system by way of STATCOM with combined PI and Fuzzy Logic controlled voltage regulator. 
Here, the efficacy and performance of the STATCOM have been analyzed by the rate of debauchery of transient energy in post fault time, which providing additional damping. The main purpose of the STATCOM is to maintain the bus bar voltage by injecting appropriate reactive power, and also it augments the dynamic performance of the power system.

Marouani et al. [13] have proposed a multi-objective evolutionary algorithm (MOEA) for solving the optimal reactive power dispatch (ORPD) problem by means of FACTS devices. This nonlinear multi-objective problem (MOP) has been solved by reducing the real power loss in transmission lines and voltage deviation at load buses simultaneously, by changing the parameters and searching optimal location for FACTS devices. The constraints of this MOP have been splitted to equality constraints described by load flow equations and inequality constraints such as, generation of reactive power sources and security limits at load buses. Two types of FACTS devices, such as SSSC and UPFC have been considered.

Moses et al. [14] have introduced a Service Oriented Architectural (SOA) model for exhibiting the transient stability of a large interconnected power system and tested for a sample of 14, 30 and 39 bus systems. The proposed model was applicable for any number of power system clients and also the stability services can be invoked by the clients without any restriction in this service oriented environment. Several power system services have been plugged into this model and the services have been made accessible at anytime and anywhere for the power system operations.

Farahani et al. [15] have presented the application of UPFC in order to maintain voltage as well as to improve stability at a Multi-Machine electric power system installed with UPFC. PI type controllers have been considered for UPFC control and the parameters of these PI type controllers have been tuned by PSO. The capability of UPFC in voltage control and also stability improvement has been exhibited by comparing the results of the proposed UPFC based system with the results without UPFC. Nonlinear time domain simulation results have proved the potency of UPFC in simultaneous control of voltage and also stability enhancement.

Murali et al. [16] have examined the enhancement of transient stability of a two-area power system via UPFC, which is an efficient FACTS device able to control the active and reactive power flows in a transmission line through controlling properly its series and shunt parameters. Simulations have been done in MATLAB/SIMULINK platform for the two-area power system model with UPFC in order to evaluate the effects of UPFC on transient stability performance of the system. Also, the performance of UPFC has been compared with other FACTS devices namely, SSSC, TCSC and SVC respectively.

Venkateswarlu et al. [19] have presented the increase in power demand, operation and planning of large interconnected power system are becoming more complex, so power system will become less secure and stable. Voltage stability is one of the phenomena which have result in a major blackout. FACTS controllers narrow the gap between the no controlled and the controlled power system mode of operation, by providing additional degrees of freedom to control power flows and voltages at key locations of the network because of their flexibility and fast control characteristics. Placement of these devices in suitable location can lead to direct in line flow and preserve bus voltages in desired level and so improve voltage stability margins. This paper presents a GA and PSO analysis based allocation algorithm for UPFC considering Cost function of UPFC device, VSI for optimal placement, Improvement of voltage profile and Reduction of power system losses. Proposed algorithm is tested on a IEEE- 5 bus and IEEE-30 bus test power system for optimal allocation of UPFC device and results are presented.

Hamid et al. [20] have introduced a new technique for identifying the most suitable generator and load buses for the purpose of preventive and corrective actions by means of FVSI-T. The method has promoted a reliable technique for ranking the priority of generator bus to be performed power scheduling and load buses for shunt element installation accurately. This can be valuable knowledge for a system operator (SO) when confronting with a problem related to voltage stability assessment and improvement. Moreover, the Artificial Intelligence based FVSI-T via Evolutionary Programming has also been promoted and the results using the developed EP algorithm is comparable to the alternative technique such as Topological Generator and Load Distribution Factor (TGLDF) method. Validation on IEEE 14-Bus and 57-Bus reliability test system (RTS) revealed that the proposed method has great capability to be applied into real system.

Sakthivel et al. [21] have proposed a PSO based optimization algorithm to crack the problem of optimal real and reactive power dispatch counting the post and sizing of SVC and TCSC device in a medium size power network for voltage stability limit enhancement and reducing the fuel cost. This work proves that voltage stability limit enhancement (stress relief) is additional effective when it is done equally by control of real and reactive power generation and power flows. Reactive power generation control is indicated by the control of generator bus voltages and VAR support due to SVC. The PSO algorithm is efficient, easy to implement and widely used in the geography of engineering. The settings of the PSO parameters are exposed to be optimal for this type of application. The algorithm is able to locate the best solutions with a relatively little number of iterations and particles, therefore with a reasonable computational effort. 
Vivek Kumar Jain et al [22] have focused a solution to reactive power optimization problem with a Hybrid particle swarm optimization (PSO) approach. This estimation on the IEEE 30-bus and IEEE 57- bus power system shows that HPSO is able to undertake global search with a fast convergence rate and a characteristic of robust computation. From the reproduction learning, it has been found that HPSO converges to the global optimum. Reproduction consequences shows that the particle swarm optimization (PSO) and genetic algorithm (GA) based reactive power optimization (RPO) algorithm is able to improve profile along with minimization in power scheme. The computational results verify its good presentation in terms of solution excellence, computational cost as well as the meeting stability.

\section{Unified Power Flow Controller (UPFC)}

A UPFC is the most promising device in the FACTS concept. It has the ability to regulate the three control parameters, i.e. the bus voltage, transmission line reactance, and phase angle between two buses. A major function of the UPFC is to redistribute power flow among transmission lines during steady state. During transients, it can be used to improve the damping of low frequency oscillations. To perform these tasks, the UPFC needs to be equipped with a power flow controller, a DC voltage regulator, and a supplementary damping controller. The basic components of the UPFC are two voltage source inverters (VSIs) sharing a common dc storage capacitor, and connected to the power system through coupling transformers. One VSI is connected to in shunt to the transmission system via a shunt transformer, while the other one is connected in series through a series transformer. The DC terminals of the two VSCs are coupled and this creates a path for active power exchange between the converters.

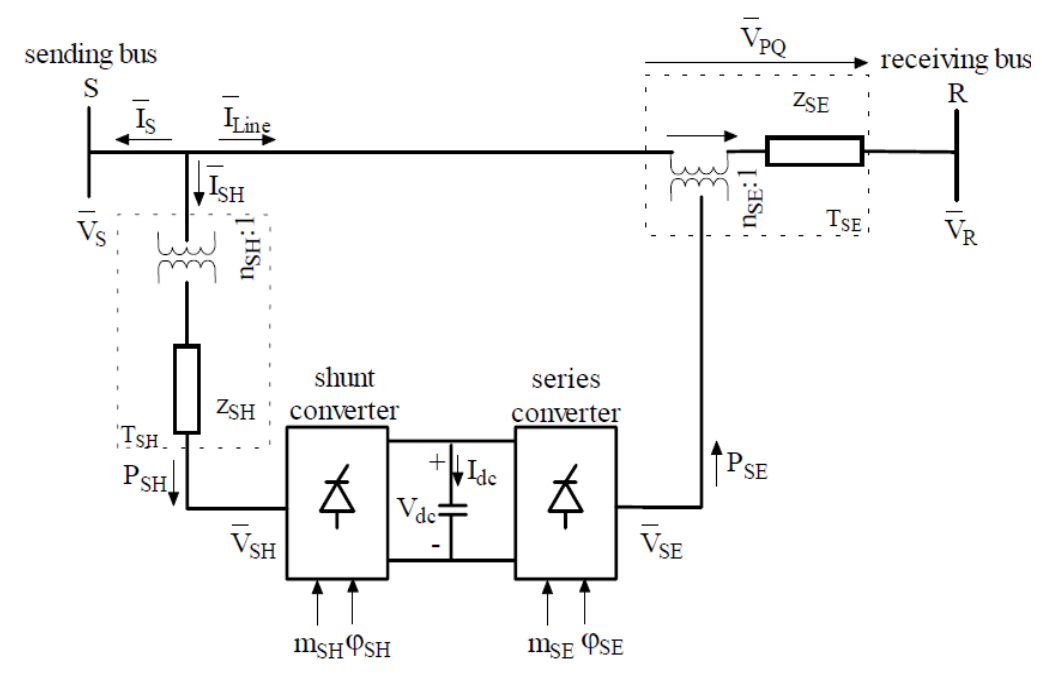

Figure 1: Structure of UPFC

The series inverter is controlled to inject a symmetrical three phase voltage system of controllable magnitude and phase angle in series with the line to control active and reactive power flows on the transmission line. So, this inverter will exchange active and reactive power with the line. The reactive power is electronically provided by the series inverter, and the active power is transmitted to the dc terminals. The shunt inverter is operated in such a way as to demand this de terminal power (positive or negative) from the line keeping the voltage across the storage capacitor $\mathrm{V}_{\mathrm{dc}}$ constant. So, the net real power absorbed from the line by the UPFC is equal only to the losses of the inverters and their transformers. The remaining capacity of the shunt inverter can be used to exchange reactive power with the line so to provide a voltage regulation at the connection point.

\subsection{UPFC Equivalent Circuit}

The UPFC equivalent circuit shown in Fig2 is used to device the steady-state model. The equivalent circuit consists of two ideal voltage sources representing the fundamental Fourier series component of the switched voltage waveforms at the AC converter terminals. The ideal voltage sources are

$$
\begin{aligned}
& V_{v R}=V_{v R}\left(\cos \theta_{v R}+\sin \theta_{v R}\right) \\
& V_{c R}=V_{c R}\left(\cos \theta_{c R}+\sin \theta_{c R}\right)
\end{aligned}
$$

Where $\mathrm{V}_{\mathrm{Vr}}$ and $\Theta_{\mathrm{vR}}$ are the controllable magnitude $\left(V_{v R \min } \leq V_{v R} \leq V_{v R \operatorname{maX}}\right)$ and angle $\left(O \leq \theta_{v R} \leq 2 \pi\right)$ of the voltage source representing the shunt converter. The magnitude $V_{c R}$ and angle $\theta_{c R}$ of the voltage sources of the 
series converter are controlled between limits $\left(V_{C R \min } \leq V_{C R} \leq V_{C R \max }\right)$ and angle $\left(O \leq \theta_{C R} \leq 2 \pi\right)$, respectively.

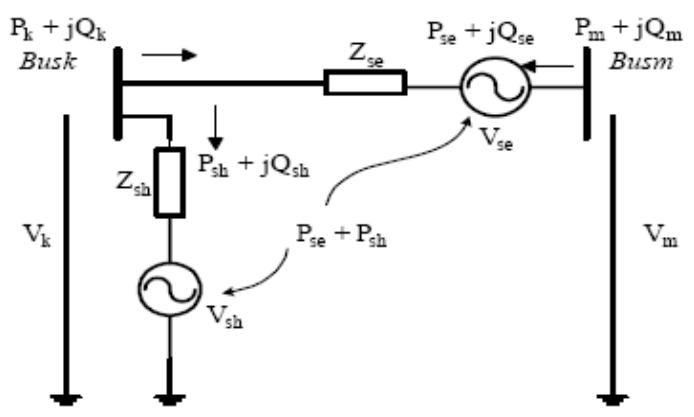

Figure 2: Voltage source model of UPFC

\section{ORPF Problem Formulation}

Optimal reactive power flow (ORPF) problem is mainly concerned with minimization active power loss of power system, subject to a choice of equality and inequality constraints. Mathematically ORPF problem may be represented as

$$
\begin{aligned}
& \operatorname{Min} J(x, u) \\
& \text { Subject to } g(x, u)=0 \text { and } h(x, u)<=0
\end{aligned}
$$

Where, $J$ is the objective function to be minimized. For loss minimization problem, $J$ can be defined as follows:

$$
\mathrm{J}=\mathrm{P}_{\mathrm{loss}}=\sum_{\mathrm{K} \in \mathrm{NTL}} \mathrm{g}_{\mathrm{k}}\left(\mathrm{V}_{\mathrm{i}}^{2}+\mathrm{V}_{\mathrm{j}}^{2}-2 \mathrm{~V}_{\mathrm{i}} \mathrm{V}_{\mathrm{j}} \cos \theta_{\mathrm{ij}}\right)
$$

Here, $\mathrm{P}_{\text {loss }}$ denotes active power loss of the power system; NTL is the number of network branches; gk is the conductance of branch $\mathrm{k} ; \mathrm{k}=(\mathrm{i}, \mathrm{j}), \mathrm{i} \in \mathrm{NB}, \mathrm{j} \in \mathrm{Ni} ; \mathrm{NB}$ is the total number of bus; $\mathrm{Ni}$ is the set of number of bus adjacent to bus $i ; \theta_{i j}$ is the voltage angle difference between bus $i$ and $j ; \mathrm{Vi}$ and $\mathrm{Vj}$ are the voltage of bus $\mathrm{i}$ and $\mathrm{j}$ respectively. $\mathrm{x}$ and $\mathrm{u}$ are the vectors of dependent and control variables respectively. The vector of dependent variables $\mathrm{x}$ may be represented as

$$
\mathrm{x}^{\mathrm{T}}=\left[\mathrm{P}_{\mathrm{G} 1}, \mathrm{~V}_{\mathrm{L} 1} \ldots . . \mathrm{V}_{\mathrm{LNPQ}}, \mathrm{Q}_{\mathrm{G} 1} \ldots . . \mathrm{QG}_{\mathrm{NPV}}\right]
$$

where, $\mathrm{P}_{\mathrm{G} 1}$ denotes the slack bus power; $\mathrm{V}_{\mathrm{L}}$ is the $\mathrm{PQ}$ bus voltages; $\mathrm{Q}_{\mathrm{G}}$ is the reactive power output of the generators; NPV is the number of voltage controlled bus; NPQ is the number of PQ bus. The vector of control variables may be written as

$$
\mathrm{U}^{\mathrm{T}}=\left[\mathrm{V}_{\mathrm{G} 1} \ldots . . \mathrm{V}_{\mathrm{GPV}}, \mathrm{T}_{1} \ldots . . \mathrm{T}_{\mathrm{NT}}, \mathrm{QC} 1 \ldots . \mathrm{Q}_{\mathrm{CNC}}\right]
$$

where, NT and NC are the number of tap changing shunt VAR compensators respectively, $\mathrm{V}_{\mathrm{G}}$ is the terminal voltages at the voltage controlled bus, $T$ is the tap ratio of the tap changing transformers and $\mathrm{Q}_{\mathrm{C}}$ is the output of shunt VAR compensators.

Here, $g$ is the set of equality constraints representing the following load flow equations:

$$
\mathrm{P}_{\mathrm{Gi}}-\mathrm{P}_{\mathrm{Di}}=\mathrm{V}_{\mathrm{i}} \sum_{\mathrm{I}=1}^{\mathrm{NB}} \mathrm{V}_{\mathrm{k}}\left(\mathrm{G}_{\mathrm{ik}} \cos \theta_{\mathrm{ik}}+\mathrm{B}_{\mathrm{ik}} \sin \theta_{\mathrm{ik}}\right)
$$

Where $\mathrm{i}=1,2 \ldots . . \mathrm{NB}$

$$
Q_{G i}-Q_{D i}=\mathrm{V}_{\mathrm{i}} \sum_{I=1}^{N B} V_{k}\left(G_{i k} \sin \theta_{i k}+B_{i k} \cos \theta_{i k}\right.
$$

Where $\mathrm{i}=1,2 \ldots . . \mathrm{NB}$

where, $\mathrm{P}_{\mathrm{Gi}}$ and $\mathrm{Q}_{\mathrm{Gi}}$ are the injected active and reactive power, $\mathrm{P}_{\mathrm{Di}}$ and $\mathrm{Q}_{\mathrm{Di}}$ are the active and reactive power demand at bus $\mathrm{i} ; \mathrm{G}_{\mathrm{ik}}$ and $\mathrm{B}_{\mathrm{ik}}$ are the transfer conductance and susceptance between bus $\mathrm{i}$ and $\mathrm{k}, \theta_{\mathrm{ik}}$ is the phase angle difference between the voltages at bus $i$ and $k$. $h$ is the set of system operating constraints which include:

\subsection{Generator Constraints}


For all Generators, including the slack, the voltages and reactive power outputs must be restricted within their permissible lower and upper limits as follows:

$$
\begin{gathered}
\mathrm{V}_{\mathrm{Gi}}^{\min } \leq \mathrm{V}_{\mathrm{Gi}} \leq \mathrm{V}_{\mathrm{Gi}}^{\max }, \max \mathrm{i}=1,2 \ldots \mathrm{NPV} \\
\mathrm{Q}_{\mathrm{Gi}}^{\min } \leq \mathrm{Q}_{\mathrm{Gi}} \leq \mathrm{Q}_{\mathrm{Gi}}^{\max }, \mathrm{i}=1,2 \ldots \mathrm{NPV}
\end{gathered}
$$

\subsection{Transformer Constraints}

Transformer tap settings must be within its specified lower and upper limits as follows:

$$
\mathrm{T}_{\mathrm{i}}^{\min } \leq \mathrm{T}_{\mathrm{i}} \leq \mathrm{T}_{\mathrm{Gi}}^{\max }, \mathrm{i}=1,2, \ldots \mathrm{NT}
$$

\subsection{Shunt VAR Compensator Constraints}

Reactive power output of shunt VAR compensators must be restricted within their lower and upper limits as follows:

$$
\mathrm{Q}_{\mathrm{ci}}^{\min } \leq \mathrm{Q}_{\mathrm{ci}} \leq \mathrm{Q}_{\mathrm{ci}}^{\max }, \mathrm{i}=1,2, \ldots \mathrm{NC}
$$

\subsection{Voltage Constraint}

Voltage of each PQ bus must be within its lower and upper operating limits as follows:

$$
\mathrm{V}_{\mathrm{Li}}^{\min } \leq \mathrm{V}_{\mathrm{Li}} \leq \mathrm{V}_{\mathrm{Li}}^{\max }, \mathrm{i}=1,2 \ldots \mathrm{NPQ}
$$

The inequality constraints of the dependant variable (like $\mathrm{P}_{\mathrm{G} 1}, \mathrm{~V}_{\mathrm{L}}, \mathrm{Q}_{\mathrm{G}}$ ) may be incorporated within the objective function as quadratic penalty terms in order to keep their final values close to their operating limits. Therefore, to account for these constraints, the objective function (1) may be modified to

$\mathrm{J}_{\mathrm{mod}}=\mathrm{P}_{\mathrm{loss}}+\lambda_{\mathrm{p}}\left(\mathrm{P}_{\mathrm{G} 1}-\mathrm{P}_{\mathrm{G} 1}^{\mathrm{lim}}\right)^{2}+\lambda \mathrm{V} \sum_{\mathrm{i}=1}^{\mathrm{NQ}}\left(\mathrm{V}_{\mathrm{Li}}-\mathrm{V}_{\mathrm{Li}}^{\mathrm{lim}}\right)^{2}+\lambda \mathrm{Q} \sum_{\mathrm{i}=1}^{\mathrm{N}} \mathrm{PQ}\left(\mathrm{Q}_{\mathrm{Gi}}-\mathrm{Q}_{\mathrm{Gi}}^{\lim }\right)^{2}$

Where $\lambda \mathrm{P}, \lambda \mathrm{V}, \lambda \mathrm{Q}$ are the penalty factors. $\mathrm{V}_{\mathrm{Li}}^{\lim } \& \mathrm{Q}_{\mathrm{Gi}}^{\lim }$ are calculated as

$$
\begin{aligned}
& V_{\mathrm{Li}}^{\lim }\left\{\begin{array}{l}
\mathrm{V}_{\mathrm{Li}}^{\max }, \mathrm{V}_{\mathrm{Li}}>\mathrm{V}_{\mathrm{Li}}^{\max } \\
\mathrm{V}_{\mathrm{Li}}^{\min }, \mathrm{V}_{\mathrm{Li}}>\mathrm{V}_{\mathrm{Li}}^{\min } \\
0, \quad \text { else; }
\end{array}\right. \\
& \mathrm{Q}_{\mathrm{Gi}}^{\lim }\left\{\begin{array}{l}
\mathrm{Q}_{\mathrm{Gi}}^{\max }, \mathrm{Q}_{\mathrm{Gi}}>\mathrm{Q}_{\mathrm{Gi}}^{\max } \\
\mathrm{Q}_{\mathrm{Gi}}^{\min }, \mathrm{Q}_{\mathrm{Gi}}>\mathrm{Q}_{\mathrm{Gi}}^{\min } \\
0, \quad \text { else; }
\end{array}\right.
\end{aligned}
$$

\section{Voltage Stability Index Computation}

Consider the power network where $\mathrm{n}$ is the total number of buses with $1,2, \ldots \ldots . . \mathrm{g}$ generator buses, and $\mathrm{g}+1, \ldots \ldots \ldots, \mathrm{n}$ remaining $(\mathrm{n}-\mathrm{g})$ buses. In this paper we have tested on the IEEE 14 and IEEE 30 bus system for a given operating condition, using the load flow results, the Voltage stability index ' $L$ ' can be calculated as

$$
\mathrm{L}_{\mathrm{j}}=\left|1-\sum_{\mathrm{i}=1}^{\mathrm{g}} \mathrm{F}_{\mathrm{ij}} \frac{\mathrm{V}_{\mathrm{i}}}{\mathrm{V}_{\mathrm{j}}}\right|
$$

where $\mathrm{j}=\mathrm{g}+1 \ldots \mathrm{n}$ and all the terms inside the sigma on the right hand side of (1) are complex quantities. The complex values of $F_{i j}$ are obtained from the $Y_{\text {bus }}$ matrix of power system. For a given operating condition:

$$
\left[\begin{array}{c}
\mathrm{V}_{\mathrm{L}} \\
\mathrm{I}_{\mathrm{G}}
\end{array}\right]=\left[\begin{array}{c}
\mathrm{Z}_{\mathrm{LL}} \mathrm{F}_{\mathrm{LG}} \\
\mathrm{K}_{\mathrm{GL}} \mathrm{Y}_{\mathrm{GG}}
\end{array}\right]\left[\begin{array}{c}
\mathrm{I}_{\mathrm{L}} \\
\mathrm{V}_{\mathrm{G}}
\end{array}\right]
$$
load nodes.

where $\mathrm{I}_{\mathrm{G}}, \mathrm{I}_{\mathrm{L}}$, and $\mathrm{V}_{\mathrm{G}}, \mathrm{V}_{\mathrm{L}}$, represent complex current and voltage vectors at the generator nodes and

$$
\begin{gathered}
{\left[\mathrm{I}_{\mathrm{G}}\right]=\left[\mathrm{I}_{1}, \ldots \ldots \ldots \ldots \ldots \ldots \mathrm{I}_{\mathrm{n}}\right]^{\mathrm{t}}} \\
\text { injected voltage of generator buses } \\
{\left[\mathrm{I}_{\mathrm{L}}\right]=\left[\mathrm{I}_{\mathrm{g}+1}, \ldots \ldots \ldots \ldots \ldots \ldots \mathrm{I}_{\mathrm{n}}\right]^{\mathrm{t}}} \\
\text { injected current of load buses } \\
{\left[\mathrm{V}_{\mathrm{G}}\right]=\left[\mathrm{V}_{1}, \ldots \ldots \ldots \ldots \ldots \ldots \mathrm{V}_{\mathrm{g}}\right]^{\mathrm{t}}} \\
\text { complex generator bus voltages }
\end{gathered}
$$


are corresponding partitioned portions of the $\mathrm{Y}_{\text {bus }}$ matrix

$$
\begin{gathered}
{\left[\mathrm{V}_{\mathrm{N}}\right]=\left[\mathrm{V}_{\mathrm{g}+1}, \ldots \ldots \ldots \ldots \ldots \mathrm{V}_{\mathrm{n}}\right]^{\mathrm{t}}} \\
\text { complex load bus voltages } \\
{\left[\mathrm{Y}_{\mathrm{GG}}\right] \ldots\left[\mathrm{Y}_{\mathrm{GL}}\right] \ldots\left[\mathrm{Y}_{\mathrm{LL}}\right] \ldots \ldots\left[\mathrm{Y}_{\mathrm{LG}}\right]}
\end{gathered}
$$

$$
\left[\begin{array}{c}
I_{G} \\
I_{L}
\end{array}\right]=\left[\begin{array}{cc}
Y_{G G} & Y_{G L} \\
Y_{L G} & Y_{L L}
\end{array}\right]\left[\begin{array}{c}
V_{G} \\
V_{L}
\end{array}\right]
$$

This analysis will be carried out only for the load buses; hence the index that to be obtained for load buses only. For stability the index L must not be more than one for any of the nodes $\mathrm{j}$. The global index for stability of the given power system is defined to be

$$
L=\text { maximumof } L_{j} \text { forallj (loadbuses) }
$$

The index far away from 1 and close to 0 indicates voltage stability. The $\mathrm{L}$ index will give the scalar quantity to each load bus. Among the various indices for voltage stability and voltage collapse forecast (i.e. far away from 1 and secure to 1 or $>1$ respectively), the $\mathrm{L}$ index will give more accurate results. The $\mathrm{L}$ indices for given loads conditions are calculated for all load buses and the maximum of the L indices gives the proximity of the system to voltage collapse.

\section{Proposed Genetic Algorithm (GA) and Particle Swarm Optimization (PSO)}

\subsection{Overview of GA}

Genetic Algorithm (GA) is one of the most legendary meta-heuristic optimization algorithms which is based on natural progression and population. Genetics which is usually used to reach to near global optimum solution. In each iteration of GA (referred as generation), a new set of string (i.e. chromosomes) with improved fitness is produced using genetic operators (i.e. selection, crossover and mutation).

\subsubsection{Selection Operator}

Key idea: give preference to better individuals, allowing them to pass on their genes to the next generation. The goodness of each individual depends on its fitness. Fitness may be determined by an objective function or by a subjective judgement.

\subsubsection{Crossover Operator}

Prime distinguished factor of GA from other optimization techniques. Two individuals are chosen from the population using the selection operator .A crossover site along the bit strings is randomly chosen. The values of the two strings are exchanged up to this point. If $S 1=000000$ and $S 2=111111$ and the crossover point is 2 then $S 1^{\prime}=110000$ and $\mathrm{S}^{\prime}=001111$. The two new offspring created from this mating are put into the next generation of the population .By recombining segment of good individuals, this process is likely to create even superior individuals.

\subsubsection{Mutation Operator}

With some low probability, a portion of the new individuals will have some of their bits flipped. Its purpose is to maintain diversity within the population and inhibit premature convergence. Mutation alone induces a random walk through the search space; Mutation and selection (without crossover) create a parallel, noise-tolerant, hill climbing algorithm.

\subsection{Overview of PSO}

PSO is initialized with a group of random particles and the searches for optima by updating updated by following "two best" values. The first one is the best solution (fitness value) it has achieved so far. This is called $\mathrm{P}_{\text {best }}$. Another value that is tracked by the particle swarm optimizer is the best value obtained so far by any particle in the population. This best value is the global best called $G_{\text {best. }}$ After finding the best values the particles updated its velocity and position with the following equation.

$$
\begin{aligned}
& V_{i}^{k+1}=W V_{i}^{k}+C_{1} * \text { rand } 1 *\left(P_{\text {besti }}-S_{i}^{k}\right)+C_{2} * \text { rand } 2 *\left(G_{\text {besti }}-S_{i}^{k}\right) \\
& S_{i}^{k+1}=S_{i}^{k}+V_{i}^{k+1} \\
& W=W_{\max }=\left(\frac{W_{\max }-W_{\min }}{\text { iter }_{\text {max }}}\right) * \text { iter }
\end{aligned}
$$

Where

$\mathrm{V}_{\mathrm{i}}^{\mathrm{k}}=$ Velocity of agent $\mathrm{I}$ at $\mathrm{k}^{\text {th }}$ iteration

$\mathrm{V}_{\mathrm{i}}^{\mathrm{k}+1}=$ Velocity of agent $i$ at $(\mathrm{k}+1)^{\text {th }}$ iteration

$W=$ The inertia weight

$\mathrm{C}_{1}=\mathrm{C}_{2}=$ Weighting factor (0 to 4$)$

$\mathrm{S}_{\mathrm{i}} \mathrm{k}^{\mathrm{k}}=$ Current position of agent at $\mathrm{k}^{\text {th }}$ iteration 
$\mathrm{S}_{\mathrm{i}}^{\mathrm{k}+1}=$ Current position of agent at $(\mathrm{k}+1)^{\text {th }}$ iteration

iter $_{\text {mac }}=$ Maximum iteration number

iter $=$ Current iteration number

$\mathrm{P}_{\text {best }}=\mathrm{P}_{\text {best }}$ of agent $i$

$\mathrm{G}_{\text {best }}=\mathrm{G}_{\text {best }}$ of the group

$\mathrm{W}_{\max }=$ Initial value of inertia weight $=0.9$

$\mathrm{W}_{\min }=$ Initial value of inertia weight $=0.2$

The velocity of the particle is modified by using (20) and position is modified by using (21). The inertia weight factor is modified according to (22) to enable quick convergence.

\subsubsection{UPFC Cost and Fitness Function}

Using Siemens AG Database [7] and [8], cost function for UPFC is developed as follows:

$$
C_{U P F C}=0.0003 S^{2}-0.2691 S+188.22 U S \$ / k V A R
$$

Where, $\mathrm{S}$ is operating range of UPFC in MVAR

$$
\mathrm{S}=\left|\mathrm{Q}_{2}-\mathrm{Q}_{1}\right|
$$

$\mathrm{Q}_{1}$ - MVAR flow through the branch before placing FACTS device.

$\mathrm{Q}_{2}$. MVAR flow through the branch after placing FACTS device.

Place FACTS devices in order to enhance voltage stability margin of power system considering cost function FACTS devices. So these devices should be place to prevent congestion in transmission lines and transformer and maintain bus voltages close to their reference. Were used in objective function considering cost function of UPFC and power system losses. Fitness function is expressed as below:

$$
\begin{array}{r}
\left.\mathrm{f}(\mathrm{x})=\mathrm{a}_{1} \max \left(\mathrm{L}_{\mathrm{j}}\right)+\mathrm{a}_{2} \text { (TotalInvestmentCost }\right)+\mathrm{a}_{3} \text { (Losses) } \\
\text { Fitnessfunction }=\frac{1}{\mathrm{f}(\mathrm{x})}
\end{array}
$$

The coefficient $\mathrm{a}_{1}$ to $\mathrm{a}_{3}$ optimized by trial and error to $2.78,0.1$ and 2.05 respectively

\section{Numerical Examples and Simulation Results}

Proposed PSO algorithm has been applied for minimization of active power loss in two different test systems, viz., IEEE 14-bus and IEEE 30-bus system. Programs have been written in MATLAB-7 language.

\section{(i) IEEE 14-Bus Power System:}

The Problem of Placement of the UPFC has been solved of the IEEE 14-Bus test system. By taking into consideration the voltage stability index value, it observed that 4-Bus is more sensitive towards system security.

The line and bus data and the minimum and maximum limits on control variables and dependent variables have been adapted. In addition, UPFC devices are connected at bus bars 4,5,7,9,10,11,12,13and 14for reactive power control.The power demand in bus 4 and the total power demand of the system is 0.3 p.u. on 100 MVA base.

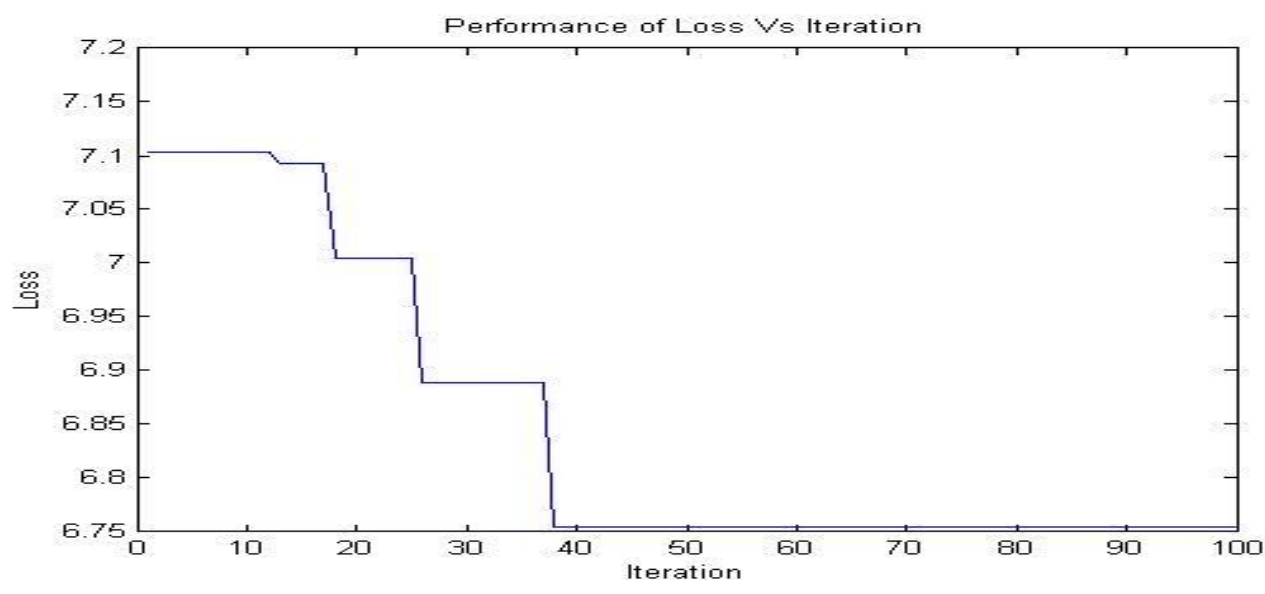

Figure 3.Performance of loss $\mathrm{v}_{\mathrm{s}}$ iteration

Table 1 Summary of results of IEEE-14 Bus Test System 


\begin{tabular}{|l|c|c|}
\hline \multicolumn{1}{|c|}{ Aspect } & GA & PSO \\
\hline Total power loss with UPFC(MVA) & 8.9798 & 6.754 \\
\hline Best Injecting Voltage is & 0.066 & 0.08 \\
\hline Best Injecting Theta is & 19 & 19 \\
\hline Best Connected Bus is & $3-4$ & $3-4$ \\
\hline
\end{tabular}

Table I evaluate the results of IEEE-14 bus test system for GA and PSO. The optimum settings of the control variables for minimization of active power loss as obtained from proposed PSO.

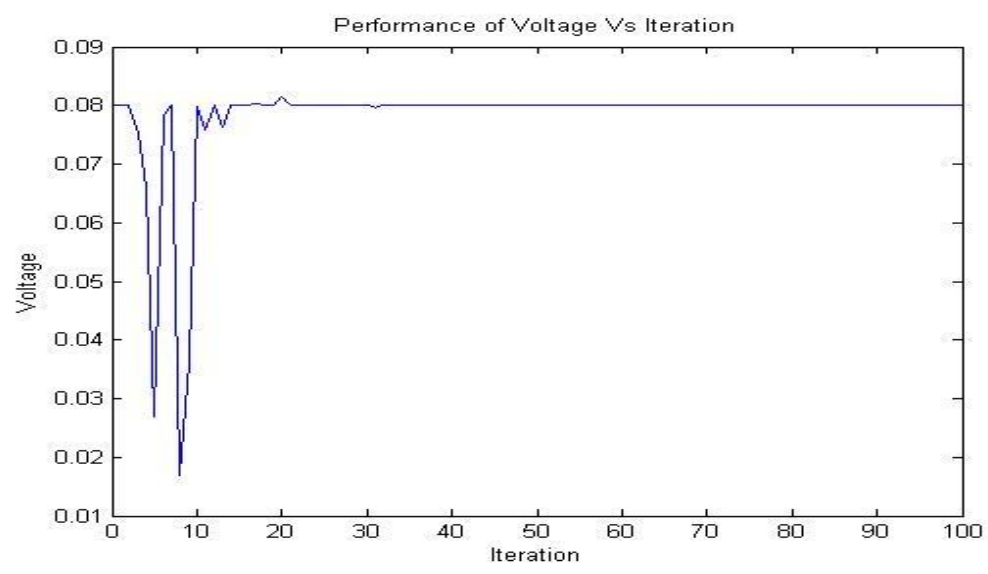

Figure 4.Performance of Voltage $\mathrm{v}_{\mathrm{s}}$ iteration

Fig. 4 Compares the voltage and iteration. The voltage level can be varied upto 10 iterations, voltage gets damped the oscillation after 10 iteration. In Fig. 5 theta get oscillated upto 40 iteration and then remains constant.

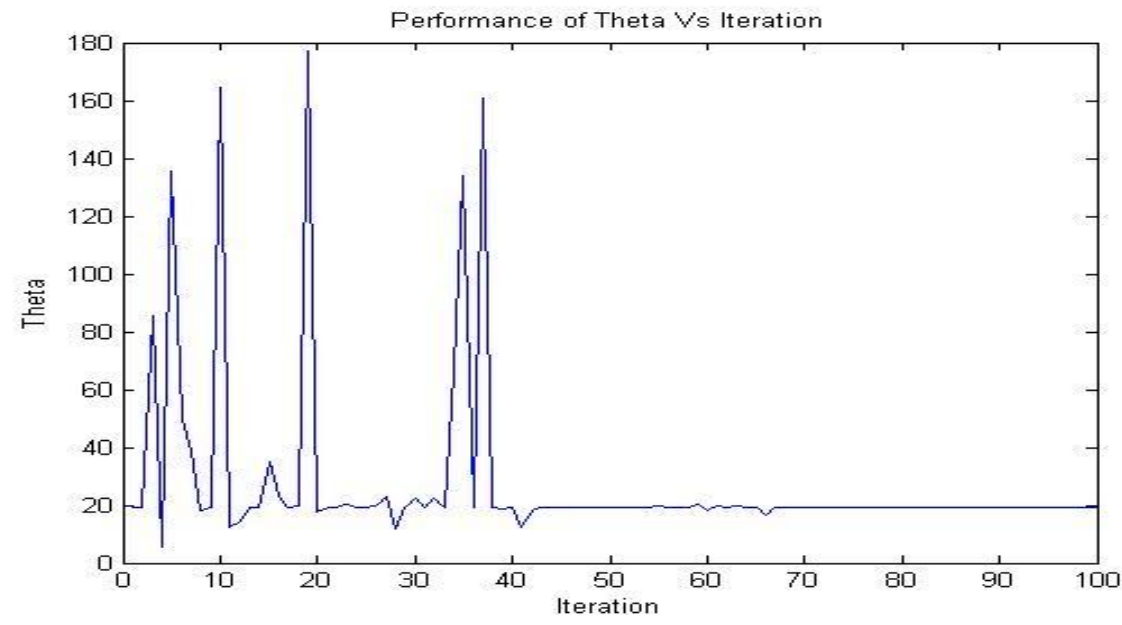

Figure 5.Performance of Theta $\mathrm{v}_{\mathrm{s}}$ iteration 


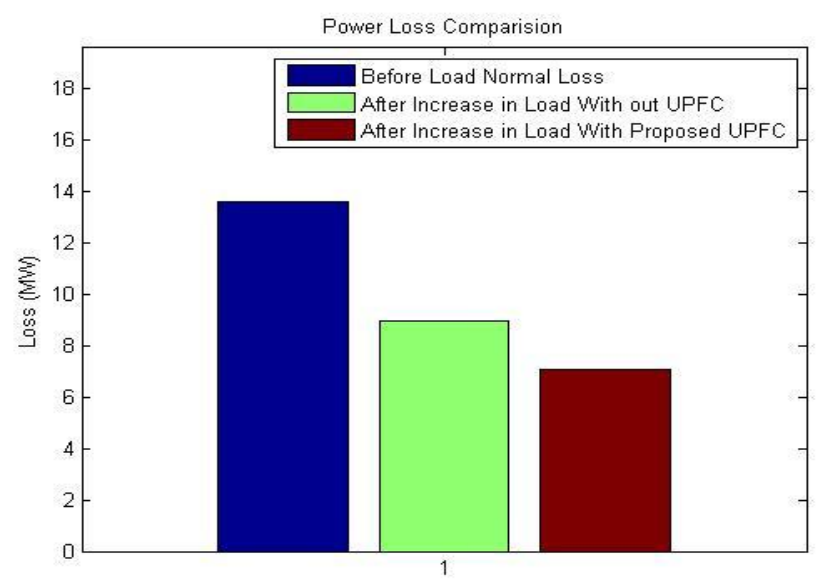

Figure 6.Power loss comparisons

\section{(ii) IEEE30-Bus Power System:}

The Problem of Placement of the UPFC has been solved of the IEEE 30-Bus test system. By considering the voltage stability index value, it observed that 30 -Bus is more sensitive towards system security. The line and bus data and the minimum and maximum limits on control variables and dependent variables have been adapted. The power demand in bus 4 and the total power demand of the system is 0.3 p.u. on 100 MVA base.

Table 2 Summary of results of IEEE-30 Bus Test System

\begin{tabular}{|l|c|c|}
\hline \multicolumn{1}{|c|}{ Aspect } & GA & PSO \\
\hline Total power loss with UPFC(MVA) & 0.18585 & 0.095879 \\
\hline Best Injecting Voltage is & 0.01 & 0.02 \\
\hline Best Injecting Theta is & 27 & 27 \\
\hline Best Connected Bus is & $2-4$ & $2-4$ \\
\hline
\end{tabular}

Table II compares the results of IEEE-30 bus test system for GA and PSO. The optimum settings of the control variables for minimization of active power loss as obtained from proposed PSO.

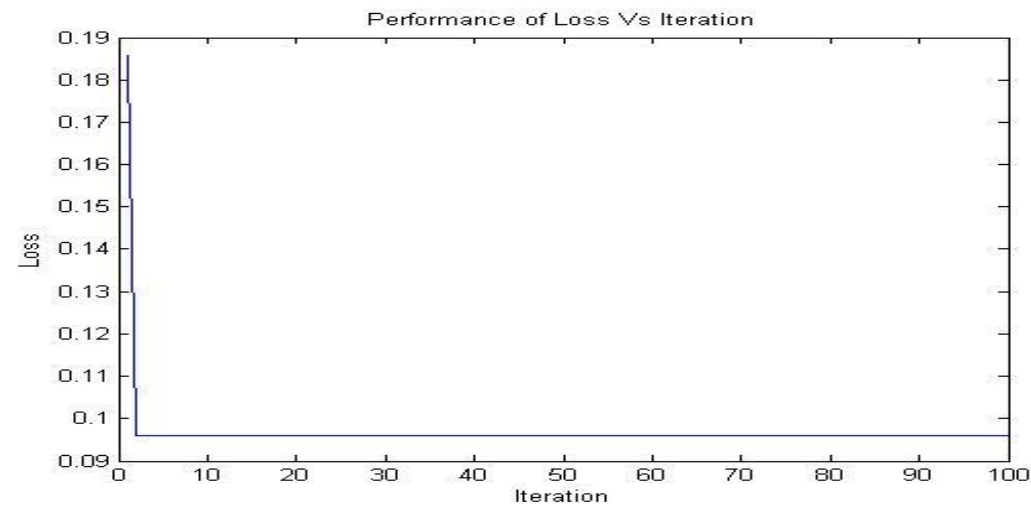

Figure 7.Performance of loss $\mathrm{v}_{\mathrm{s}}$ iteration 
Fig 7 gives the result of loss performance with respect to iteration. Loss get decreased before 5 iteration ,then remains constant for IEEE 30 bus system. The loss is approximately 0.08. In Fig 8 the voltage oscillated upto 20 iteration, after that maintained constant.

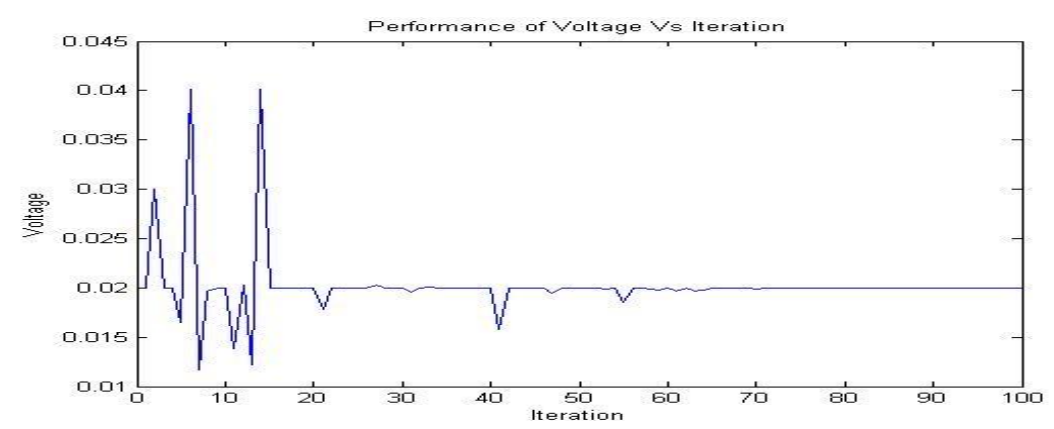

Figure 8.Performance of voltage vs iteration

Fig 9 compares the theta and iteration. The theta can be varied upto 50 iterations, theta gets damped the oscillation after 50 iteration.

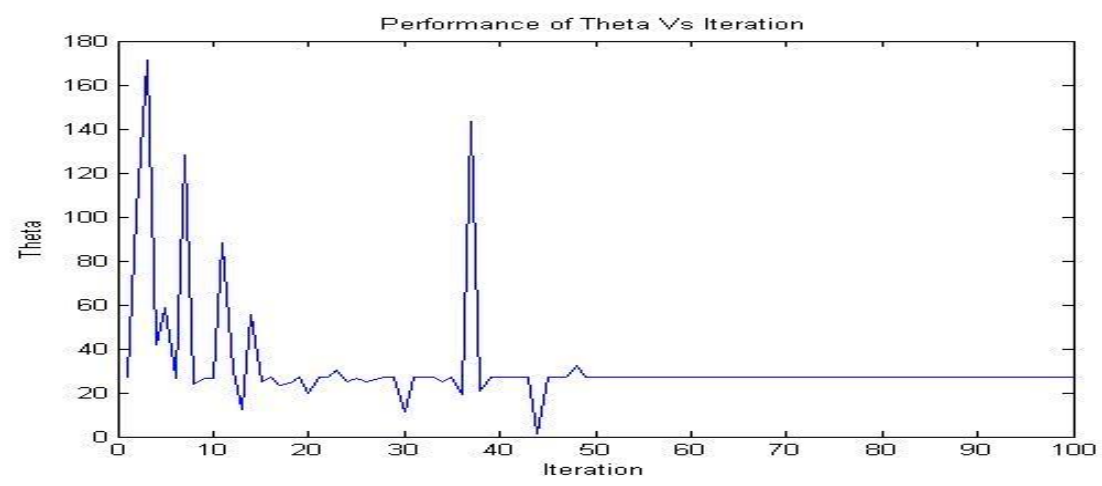

Figure 9.Performance of Theta $\mathrm{v}_{\mathrm{s}}$ iteration

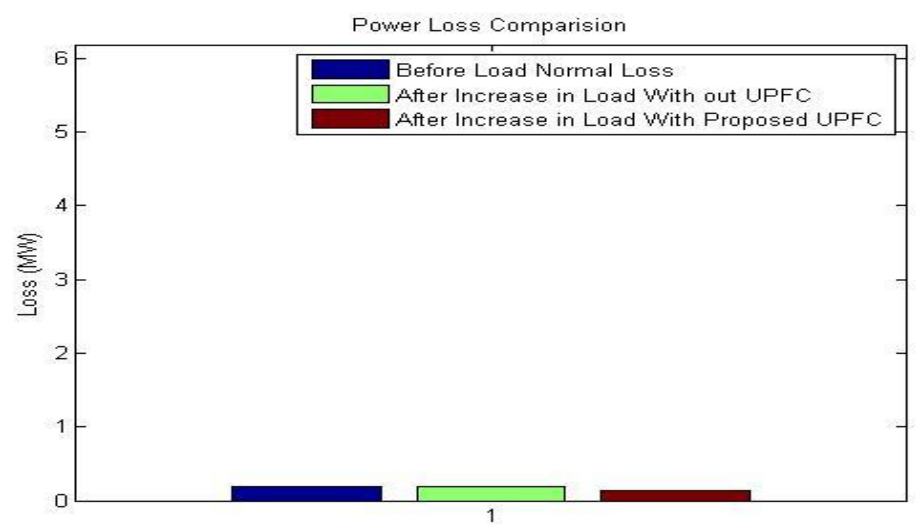

Figure 10.Power loss comparisons

\section{Conclusion}

This paper presents the application of Particle Swarm Optimization (PSO) technique in power system with and without UPFC. Results show that the real power loss and voltage violation have been significantly reduced after optimization using the proposed method. Also, the simulation results demonstrate that PSO can be successfully applied to practical power system. The power loss occurring in the various branches and state variables of IEEE bus-14 and IEEE bus-30 systems are evaluated using Particle Swarm Optimization. From the results it is concluded that the system performs recovered when the UPFC is connected i.e., the state variables are greater and the total losses are mitigate. 


\section{References}

[1] N.G.Hingorani, L.Gyugyi, Understanding FACTS, \|Concepts and Technology of Flexible AC Transmission Systems. IEEE press, 2000.

[2] L.gyugi, - A unified power flow concept for flexible AC transmission systems, IIEEE proc.c 139(4)1992.

[3] L. Gyugyi, C. D. Schauder, S. L. Williams, T.R. Reitman, D. R. Torgerson, and A. Edris, "The unified power flow controller: A newapproach to power transmission control,’IEEETrans. Power Delivery, vol. 10, pp.1085-1097, Apr. 1995.

[4] Konstantinos E. Parasopoulos and Michael N. Vrahatis, "On the Computation of All Global Minimizers Through Particle Swarm optimization", IEEE Trans. On Evolutionary Computation, vol. 8, No. 3, June 2004

[5] Kennedy and R. Eberhart, Particle Swarm Optimization, Proc. of IEEE International Conference on Neural Networks, Vol.IV, pp.1942-1948, Perth, Australia, 1995.

[6] M. Kowsalya, K. K. Ray and D. P. Kothari, "Loss Optimization for Voltage Stability Enhancement Incorporating UPFC Using Particle Swarm Optimization”, Journal of Electrical Engineering \& Technology Vol. 4, No. 4, pp.492 -498, 2009.

[7] LijiunCai, and IstvanErlich, "Optimal choiceand allocation of FACTS Devices usingGenetic Algorithms," ISAP IntelligentSystems Application to Power Systems, August 31-September 3, 2003.

[8] http://www.siemens/td.com/trancSys/pdf/cost/effectiveReliabTrans.pdf

[9] K. Lee, Y. Park and J. Ortiz, "A united approach to optimal real andreactive power dispatch", IEEE Trans PwrApparSyst vol. PAS104, no.5, pp. 1147-1153, 1985.

[10] The IEEE 57-Bus Test System, Available online:http://www.ee.washington.edu/research/pstca. .

[11] K. Mahadevan, P. S. Kannan, ”Comprehensive learning Particle SwarmOptimization for Reactive Power Dispatch,” Int. J. Applied Soft Computing, vol. 10, no. 2, pp. 641-652, March 2010.

[12] D.K. Sharma and Aziz Ahmad, "Improvement of Power System Stability by Modeling and Designing of Cascade PI and Fuzzy Logic Controllers for STATCOM", International Journal of Engineering Science and Technology, Vol.3, No.8, pp. 6543-6553, Aug 2011.

[13] Ismail Marouani, TawfikGuesmi, HsanHadjAbdallah and AbdarrazakOuali, "Optimal Reactive Power Dispatch Considering FACTS Device", Leonardo Journal of Sciences, Issue 18, and pp. 97-114, Jun 2011.

[14] J. Jegatheesan and A. Nazar Ali, "Improvement of Transient Stability Performance Using Adaptive Neuro-Fuzzy for FACTS Controllers", African Journal of Scientific Research, Vol. 6, No. 1, pp. 291-304, 2011.

[15] Shoorangiz Shams ShamsabadFarahani, HossainTourang, BehrangYousefpour, Mehdi GhasemiNaraghi and Seyed Ali Mohammad Javadian, "Effect of UPFC Tuned Based on Particle Swarm Optimization on Dynamic Stability Improvement in Power Systems", Research Journal of Applied Sciences, Engineering and Technology, Vol. 3, No. 11, pp. 1310-1314,2011.

[16] Murali, M. Rajaram and Reka, "Comparison of FACTS Devices for Power System Stability Enhancement", International Journal of Computer Applications, Vol.8, No.4, pp. 30-35, Oct 2010.

[17] Mark NdubukaNwohu, "Voltage Stability Improvement using Static Var Compensator in Power Systems", Leonardo Journal of Sciences, Issue 14, pp. 167-172, Jun 2009.

[18] M. Balasingh Moses, V. Ramachandran and P. Lakshmi, "An Effective Service Oriented Model for Power System Transient Stability Analysis", International Journal of Computer and Electrical Engineering, Vol.3, No.1, pp. 94-100, Feb 2011.

[19] K. Venkateswarlu, Ch. Saibabu, "A New valutionary algorithms used for Optimal location of UPFC on power system", Journal of Theoretical and Applied Information Technology, 2010.

[20] Z. Hamid, I. Musirin, M. M. Othman, M. N. A. Rahim, "bus priority ranking via stability index Tracing and evolutionary programming”, Journal of Theoretical and Applied Information Technology 15th February 2012. Vol. 36 No.1.

[21] S.Sakthivel, Dr.D.Mary, "OPF Based Stress Relief and Global Voltage Stability Limit Improvement using Two-Bus Equivalent Model", International Journal of Emerging trends in Engineering and Development, Issue 2, Vol.1, January-2012.

[22] Vivek Kumar Jain,Himmant Singh, "Hybrid Particle Swarm Optimization Based Reactive Power Optimization”, International Journal Of Computational Engineering Research,ISSN: 2250-3005, Mar-Apr 2012, Vol. 2 , Issue No.2. 